\title{
Patterns of Introducing Innovations in the Digital Age and Their Impact on Managerial Staff and Employees
}

\author{
Elena Zaborova, Tatiana Markova*, and Natalia Tonkikh \\ Ural State University of Economics, 620144 Ekaterinburg, Russia
}

\begin{abstract}
The modern digital era is characterized by rapid introduction of innovations in all spheres of society. The process of introducing innovations in the digital era does not happen by chance, there can be traced a number of regular patterns - steadily repeating, objective and significant trends. Some of these patterns have already been conceptualized and can be used as a methodological basis for studying the process of introducing innovation into the economic sphere. The article aims to consider the most important patterns of innovation introduction - dynamic equilibrium, the adaptation of innovation and the environment, the complication of organizational structures, changes in the innovative effect, the complexity of the innovative process, and social discomfort. The main research question is how much managers and employees are ready to accept innovations and how they respond to them. The authors also analyse how innovation patterns affect labour potential components of managers and employees: at the physical, mental and intellectual levels. It is concluded that it is vital to research further into the key patterns of innovation introduction as this contributes to better understanding of how managers' and employees' labour potential can be enhanced. One should not relate one or another component of labour potential to a specific pattern, they are most likely to manifest themselves comprehensively.
\end{abstract}

\section{Introduction}

The modern digital era is characterized by the rapid introduction of innovations in all spheres of society, including labour force. The topic of research is relevant due to the inevitability of digitalization and the need to adapt to it all the structural elements of society, including the economy and the human resources management system. Currently, the Program "Digital Economy of the Russian Federation", approved by Order of the Government of the Russian Federation dated July 28, 2017 no. 1632, classifies Industry 4.0 technologies as promising and top priority objectives for Russia's further development.

Modern innovations are characterised by cutting-edge scientific and technological development, they are based on brand new computer software able to process large amounts of information (big data) [1]. This enables organisations both to deal with customers and perform internal production, organizational and management operations on a

\footnotetext{
*Corresponding author: tmark@mail.ru
} 
new information base [2, 3]. There are many factors that affect the way how an organization or company implements innovations [1, 4]. Increasingly, innovation means not just the computerization of operations and activities, but sometimes their complete displacement with robotics [5].

The process of introducing innovations in the digital era does not happen by chance, there can be traced a number of patterns, i.e. steadily repeating, objective, significant trends. Scientists continue to search for these patterns, the problem has not yet been completely solved, but what makes this task relevant, is understanding that awareness of the innovation patterns will ensure flexibility and effectiveness of management processes as well as will help to avoid a number of errors.

The introduction of innovation is not simple, it encounters a series of obstacles, among which there are economic (financial), organizational and managerial aspects. However, the most powerful obstacle is labour potential - the quality of workers at both the managerial and front-line levels. How ready are managers and employees to embrace innovation? How ready are they for tension and retraining? What are the risks to innovation in the information and digital age? How do managers and employees respond to the patterns of innovation in the digital age? Currently, the search for answers to these questions is going on quite intensively at both the empirical and theoretical levels.

\section{Literature review}

A. I. Prigozhin argues that the concept of 'innovation' refers not only to the creation and dissemination of innovations, but to such changes, which are significant in nature, are accompanied by changes in the ways activities are performed, in style of thinking. The category of novelty belongs not so much to time as to the qualitative features of changes $[6,7]$.

A regular pattern is an objectively existing, repetitive, significant connection between the phenomena of public life or the stages of the historical process. N. S. Danakin and I. V. Konev [8] refer to regular patterns such patterns as the law of dynamic equilibrium, the adaptation of innovation and the environment, the complication of organizational structures, changes in the innovative effect, the complexity of the innovative process, social discomfort. In addition, the authors also highlight several patterns that, in our opinion, cause objection, require clarification. In our opinion, "the pattern of the superiority of product innovations", which means making an emphasis on products, equipment and technology modernization is not always implemented. Nowadays supporting processes can themselves can be subject to innovations, leading to all subsequent stages of the production process, including production. For example, information marketing technologies for data collection and advertising underlie the success of any firm [9]. The authors also highlight the "pattern of potential regression" - the failure of the first innovation discredits subsequent ones. In our opinion, failure both discredits and adjusts to innovations, it all depends on the viewpoint of senior staff and the creative potential of employees; "pattern of radiation" - innovation in one area causes a chain of changes in other, related areas (largely coincides with the pattern of complexity). Taking into account the comments made, the patterns proposed by N. S. Danakin and I. V. Konev [8] can be used as a methodological basis for studying the process of introducing digital innovations into the activities of firms and organizations, and their impact on managers and workforce.

Managerial staff and employees form in their totality the labour potential of the company. This is one of the main subsystems of human potential. The carriers of the former are only able-bodied citizens, the latter refers to the entire population of the country (including people younger and older than working age). Labour potential is a term that captures the totality of qualities that determine the ability and readiness to perform labour 
functions [10]. In its structure, it reflects the physical, mental and sociocultural components of the personality in terms of their readiness for work. The physical component includes a state of health, physical development, endurance, etc., correlated with sex and age; the mental component - stress tolerance, responsibility, conscious maturity, interest, involvement in the economic activity of the enterprise, creativity, etc. The socio-cultural component of labour potential is formed by competencies that consist of three elements: knowledge of new technologies, the ability to implement this knowledge and the ability to learn collectively, i.e. the ability to absorb knowledge. This is the amount of general and specialized knowledge, skills that determine the ability to perform work activities of a certain quality.

Each type of work involves its own set of requirements for a person, therefore, the labour potential in its specific expression will always be specific both for different areas of economic activity and for different categories of workers. Integration of employees' qualification and personal properties is a condition for safe functioning of complex technological systems [11].

The quality of labour potential, i.e. the totality of health, mental development, knowledge and skills ultimately determine the effectiveness of introducing consistent patterns of innovation in the digital age.

\section{Discussion}

N. S. Danakin and I. V. Konev [8] identify several regular patterns for introducing innovations at organizational level. Firstly, there is distinguished the "pattern of dynamic equilibrium" - innovations violate the balance in the system, but it is always necessary to find a balance between the trends of functioning and change, and ensure a flexible balance of the organizational system. What qualities are required from the manager and employees and what risks arise in this case? The need to maintain the work process without failures means that the manager has the knowledge and skills to flexibly lead the subordinates. At the physical level, this is always increased tension, including increased work time to obtain new knowledge and acquire new skills.

Secondly, "the regularity of the adaptation of innovation and the environment" innovations inevitably face multiple transformations in various areas of implementation, any implementation is unique to a certain degree. This means that the introduction of innovations requires both managers and employees to be creative, able to generate original and independent solutions. In many cases, information and digital innovations are introduced due to the decisions made by a truly competent person in this area, "a decision based on their technological and moral responsibility, on their awareness and foresight. How the information will be processed, which solution will be chosen, largely depends on the ability to ensure that the complexity does not turn into chaos and destruction" [11].

Thirdly, the "pattern of complication of organizational structures" is the complication of relationships, the strengthening of dependence between various components of the entire system, i.e. its "density". Innovation makes economic systems more interconnected with others, both within and outside a single economic field. The information and digital era is characterised by great openness, transparency of systems, from the viewpoint of control over employees' activities. Managers and employees are required to perform tasks properly and in a timely manner. Undoubtedly, the employee's psycho-physiological tension is rising, and can cause stress. Risks and responsibilities are also increasing, which is fraught with different forms of evasion from innovations, resistance. Investing resources in new ideas is a risky matter, but risk is an integral characteristic of the innovative process.

Fourthly, the "pattern of changes in the innovative effect" - the result of innovation at the experimental stage is usually higher than when it is replicated, one-time effects are 
weakened while the total effect increases. At the stage of mass implementation, many large and small unaccounted problems are discovered that smooth out the effect of the innovation. Managers and employees may be frustrated with expectations, loss of investment, and inefficiency of their effort.

Fifthly, "the pattern of the innovation process complexity" - innovation is more successful, when it covers not one narrow area, but includes related ones: not only production, but management, marketing, staff training, finance, sales. For the manager, this pattern requires such qualities as complexity and breadth of thinking, for the employee - an increase in the level of competencies, readiness to work in new conditions at all stages of the production cycle.

Sixthly. The authors distinguish the staff attitude and reactions to innovations and determine them as the pattern of "social discomfort" - the mandatory presence of social discomfort, coupled with the desire to overcome it. Modern innovations are fundamental, profound in nature, they often require reengineering the entire business process. As M. Hammer and J. Champi noted, "the inability of managers to anticipate the inevitable resistance of workers caused by reengineering and to prepare for it in a timely manner is the main reason for the failures" [12]. Such staff resistance reduces the effectiveness of innovative changes.

\section{Conclusions}

Thus, the patterns of innovation affect all components of the labor potential of managers and employees. In the end, all of them result in a system of motives for activities, the formation and management of which constitutes the main management objective.

The introduction of innovations requires business process reengineering - that is fundamental rethinking to achieve the maximum effect from production, economic and financial activities. Only the joint involvement of a significant number of employees and managerial staff into the transformation process can push their integral team to the necessary structural changes.

It is vital to continue research into the key patterns of innovation introduction as this contributes to better understanding of how managers' and employees' labour potential can be enhanced. We tend to think that one should not relate one or another component of labor potential to a specific pattern, most likely they manifest themselves comprehensively. Further research should also focus on deeper understanding of the factors that reduce staff resistance to innovation.

\section{Acknowledgements}

The research was carried out with the support of the Russian Foundation for Basic Research in the framework of the scientific project No. 19-010-00705 Development of tools for assessing the impact of social pollution of labor relations on the workers' wellbeing in the digital economy.

\section{References}

1. W. Bartz-Zuccala, P. Mohnen, H. Schweiger, Comp. Econ. Stud., 60 (2018)

2. T. J. Marion, S. K. Fixson, J. Prod. Innov. Manag., 8 (2020)

3. J. D. Johnson, Int. J. Innov. Tech. Manag., 15 (2018)

4. K. Okatan, O. B. Alankus, JOSI, 6 (2019) 
5. M. A. Vieira Graglia, P. Giannoccaro Von Huelsen, J. Innov. Sustain. RISUS, 11 (2020)

6. Prigozhin, A. I. Innovations: Incentives \& Obstacles (1989)

7. N. I. Lapin, A. I. Prigozhin et al., The Structure of the Innovation Process (1981)

8. N. S. Danakin, I. V. Konev, City Manag. Theory \& Practice, 4 (2015)

9. L. M. De Luca, D. Herhausen, G. Troilo, A. Rossi, J. Acad. Mark. Sci., 8 (2020)

10. E. I. Chizhikova, City \& Urban Manag., 1 (2014)

11. T. Yu. Semenova, City \& Urban Manag., 1 (2014)

12. M. Hammer, J. Champi, Reengineering the Corporation (1993) 